\title{
Experience and yield of mass breast screening among working women in major cities of India: a mixed-method study
}

\author{
Rakshita Bhutale $^{1 *}$, Rajani V.2, Varsha Bhashyakarla $^{2}$, Srinivas Gunda $^{3}$, Archana Bhat ${ }^{4}$
}

\begin{abstract}
${ }^{1}$ Department of OBG/ FRM, ${ }^{2}$ Department of Care team, ${ }^{3}$ Department of Paediatrician and Clinical Strategy Lead, Mfine (Novocura Tech Health Services Pvt Ltd), Bangalore, Karnataka, India

${ }^{4}$ Department of Evidence Scientist, Evidencian Research Associates, Bangalore, Karnataka, India
\end{abstract}

Received: 07 August 2020

Accepted: 09 September 2020

\author{
*Correspondence: \\ Dr. Rakshita Bhutale, \\ E-mail: dr.rakshita@mfine.com
}

Copyright: (c) the author(s), publisher and licensee Medip Academy. This is an open-access article distributed under the terms of the Creative Commons Attribution Non-Commercial License, which permits unrestricted non-commercial use, distribution, and reproduction in any medium, provided the original work is properly cited.

\begin{abstract}
Background: iBreast ${ }^{\mathrm{TM}}$ tool is simple, safe, a handy device which is designed for mass breast cancer screening tool in a community or hospital setting. This study determined the yield and basic characteristics of women attending the breast cancer screening programme. The study also determined the overall experience of women who underwent breast cancer screening using iBreast ${ }^{\mathrm{TM}}$ tool.

Methods: This study was a multicentric, retrospective observational study conducted in Mumbai, Bangalore, Chennai and Hyderabad as a part of routine work-place breast cancer screening programme supported by Mfine. Screening was done by $\mathrm{iBreast}^{\mathrm{TM}}$, which is a hand-held compression device. After proper clinical examination and iBreast ${ }^{\mathrm{TM}}$ scanning, results were confirmed by a consultant trained in interpretation of findings. The overall experience of the women who underwent screening was also determined using a questionnaire. Descriptive analysis was carried out by mean and standard deviation for quantitative variables, frequency and proportion for categorical variables. The qualitative assessment and thematic analysis of the qualitative data was done.

Results: A total of 1080 eligible female employees were present in the approached IT companies and out of that 451 women $(41.75 \%)$ had consented and participated in the screening program. The acceptance rate was highest in Bengaluru city (65\%) followed by Mumbai (53\%), Chennai (33\%) and least in Hyderabad (18\%). 31 participants documented positive findings had in the scan and were referred for further evaluation. The quantitative and qualitative data determined that iBreast ${ }^{\mathrm{TM}}$ scan was highly accepted by all participants. Customer service, screening location and overall experience was deemed good by the participants with an average score of 4.8 .

Conclusions: The iBreast ${ }^{\mathrm{TM}}$ has the potential to be a promising tool in providing effective diagnosis after breast examinations.
\end{abstract}

Keywords: Breast cancer, iBreast ${ }^{\mathrm{TM}}$ exam, Mammography

\section{INTRODUCTION}

Breast cancer is the most common malignancy among women worldwide, representing nearly a quarter of all cancers and in India, it accounts for $14 \%$ of all cancers in women. ${ }^{1,2}$

In a span of 4 years from 2008-2012, India faced a challenging rise of $11.54 \%$ occurrence and $13.28 \%$ rise in mortality of breast cancer cases. ${ }^{3}$ It can occur at any age, but the incidence begins to rise in the early thirties and peak at ages 50-64 years (WHO, 2019). ${ }^{2}$

In the majority of resource-poor settings, a high proportion of breast cancer cases are diagnosed at an advanced stage. This contributes to higher morbidity, mortality, health care costs, and poor quality of life among affected women., ${ }^{4,5}$ Poor access and 
underutilization of screening services is the primary reason for the delay in diagnosis. ${ }^{1}$ Measures aimed at early breast cancer detection are reported to have a significant positive impact on cure rates, morbidity and mortality. Accessibility to early screening services coupled with efforts to increase the awareness levels of women have been regarded as the two key strategies in this regard..$^{4,6}$

Mammography is the most widely used screening modality for breast cancer in many settings. But the availability of Mammography is still limited to urban environments in resource-poor developing nations. Also, the cost and complexity make it not amenable for adaptation as a screening tool. Breast cancer screening relies on breast self-examination and clinical breast examination, which are quite subjective and can't detect subclinical lesions. ${ }^{7,8}$ These concerns prompt us to look for cheaper, easy and accessible means of screening to make an impact at the national level.

iBreast $^{\mathrm{TM}}$ is a simple, non-invasive, handheld device amenable for use as a mass screening tool in non-hospital settings. The device is radiation-free, which can also be operated by grass-root health workers with minimal training. ${ }^{9}$ It contains lead zirconate titanate piezoelectric cantilever sensor which precisely detects atypical, abnormal parts of the breast by comparison of the degree of deflection. ${ }^{10}$ This could be a potential powerful screening tool in resource-poor and highly populated nations like India. ${ }^{9}$ Studies documenting the acceptance of a device-based mass screening for breast cancer in a non-hospital setting are scarce. Also, the diagnostic yield and women's experience with iBreast ${ }^{\mathrm{TM}}$ device is not yet well studied. This study aimed to analyze the age distribution, history of any breast-related symptoms and family history of breast cancer in routine breast cancer screening programme held for female attendees working in the IT sector in selected metropolitan cities in India. To determine the yield (proportion of women with positive findings out of total women screened) of the breast cancer screening programme among the study population and explore the overall experience of women who underwent breast cancer screening using iBreast ${ }^{\mathrm{TM}}$ tool.

\section{METHODS}

The study was a multicentric, retrospective observational study. The breast cancer screening programme was conducted in Mumbai, Bangalore, Chennai and Hyderabad as a part of routine workplace health check-up supported by Mfine.

The convenience sampling technique was used to collect the sample in the study. The data collection for the study was done between January 2018 to December 2019.

Women 18 years of age or older who underwent breast cancer screening as part of a workplace comprehensive health check. Women with history of breast cancer, inflamed or ulcerated lesions, abscesses or fungating growths were excluded.

All the women at the workplace setting were educated on the need for breast cancer screening, the complete details of the procedure and further steps to be followed depending on the screening test result. A complete printed copy of the participant information sheet was provided to each woman in the English language. Any concerns regarding the procedure or results were addressed by a team led by a qualified gynaecologist. All the participants provided informed digital/written consent to undergo screening.

Waiver of participant consent for utilizing the data for the study was obtained from the ethical committee, and the study was approved by the Digital Health Research Independent Ethics Committee (approval number: DHRIEC/SAL03/21052020, dated: 21.5.2020).

\section{Screening tool}

Screening was done by iBreast ${ }^{\mathrm{TM}}$, which is a hand compression probe containing a four $\times$ four array of piezoelectric tactile pressure sensors, a custom-built electronic board and a tablet. It determines tissue elasticity difference between hard and stiff breast tumours in comparison to healthy breast tissue and measures the subtle displacements electrically. It communicates wirelessly with a mobile device to display and store the findings in real-time. The iBreast ${ }^{\mathrm{TM}}$ records the data and collects into four $\times$ four array map of the breast. This map is usually divided into sectors demarcated by three consecutive hours of a clock to directly compare to the positioning clock assigned by Mammography or ultrasonography. Green indicates healthy breast tissue while red indicates a lesion. All the iBreast $^{\mathrm{TM}}$ evaluations were performed by qualified and trained staff.

\section{Screening procedure}

The screening procedure was performed in a supine position on the examination table in a secluded room. After initial calibration of the device in an uninvolved breast area for each breast quadrants, the testing was done in quadrant wise fashion. It was detected meaning these females were advised further testing to characterize the lesion. As designed to be a pre-screening tool to identify all lesions and not cancerous lesions; the positive and negative classification for this study includes the presence or absence of clinically relevant detectable lesions. After proper clinical examination and $\mathrm{iBreast}^{\mathrm{TM}}$ scanning, iBreast ${ }^{\mathrm{TM}}$ results were confirmed by a consultant trained in the interpretation of findings. Physical examination of the breast was also done conventionally by a qualified female gynaecologist. ${ }^{11}$ Women found with positive lesions were provided with appropriate post-test counselling and were referred for further screening. Participants who were found negative 
were educated about breast cancer and were counselled about the need to perform regular breast self-examination and undergo regular screening.

We also determined the overall experience of the women who underwent screening. All the participants were asked to rate their experience on a scale of 0 to 5 ( 0 being poor and 5 being great) using a questionnaire. The rating was done on four domains including overall experience, room ambience/ cleanliness, customer service and Scan. Average rating of all the four domain-specific responses was also calculated.

\section{Operational definitions}

The acceptance rate of the screening procedure was defined as the percentage of women who provided informed written consent and underwent the procedure out of total women provided pre-screening counselling and sought consent. The yield was defined as the percentage of women found with positive lesions out of total women who underwent screening.

\section{Statistical methods}

The yield was considered as primary outcome variables. Age, family history ad symptoms will be considered as primary explanatory variables. Descriptive analysis was be carried out by mean and standard deviation for quantitative variables, frequency and proportion for categorical variables. IBM SPSS version 22 was used for statistical analysis. ${ }^{12}$ At the end of the programme, the qualitative assessment of the participants was done to determine their experience with the screening programme. Thematic analysis of the qualitative data was done to analyze the data.

\section{RESULTS}

A total of 1080 eligible female employees were educated on the protocol out of which, $41.75 \%$ consented for the iBreast examination. The approached IT companies and out of that 451 women $(41.75 \%)$ had consented and participated in the screening program. The acceptance rate was highest Bengaluru city $(65 \%)$ followed by Mumbai (53\%), Chennai (33\%) and least in Hyderabad (18\%) (Table 1).

Table 1: Overall city wise summary of the overall screening activity.

\begin{tabular}{|llll|}
\hline City & $\begin{array}{l}\text { Total number of } \\
\text { female employees }\end{array}$ & $\begin{array}{l}\text { Total number } \\
\text { screened }\end{array}$ & $\%$ \\
\hline Bengaluru & 300 & 194 & 65 \\
\hline Chennai & 700 & 232 & 33 \\
\hline Mumbai & 30 & 16 & 53 \\
\hline Hyderabad & 50 & 9 & 18 \\
\hline Total & 1080 & 451 & 41.7 \\
\hline
\end{tabular}

Majority of the participants $42.57 \%$ were aged 25 to 29 years, followed by $19.95 \%$ participants between 30 to 34 years, $19.51 \%$ participants were <24 years and $12.41 \%$ participants were between 40 to 44 years age group (Table 2).

Table 2: Age profile of the women screened and women with positive symptoms.

\begin{tabular}{|lll|}
\hline $\begin{array}{l}\text { Age distribution in } \\
\text { years }\end{array}$ & Number & $\%$ \\
\hline$<\mathbf{2 4}$ & 88 & 19.51 \\
\hline $\mathbf{2 5}$ to $\mathbf{2 9}$ & 192 & 42.57 \\
\hline $\mathbf{3 0}$ to $\mathbf{3 4}$ & 90 & 19.95 \\
\hline $\mathbf{3 5}$ to 39 & 56 & 12.41 \\
\hline $\mathbf{4 0}$ to 44 & 19 & 4.21 \\
\hline $\mathbf{4 5}$ to 49 & 4 & 0.88 \\
\hline More than $\mathbf{5 0}$ & 0 & 0 \\
\hline Total & 451 & 100 \\
\hline
\end{tabular}

Table 3: Family and personal history.

\begin{tabular}{|lll|}
\hline City & $\begin{array}{l}\text { Family } \\
\text { history } \\
\mathbf{N}(\%)\end{array}$ & $\begin{array}{l}\text { Personal } \\
\text { history } \\
\mathbf{N}(\%)\end{array}$ \\
\hline Bengaluru $(\mathbf{n = 1 9 4 )}$ & $39(20.10)$ & $50(25.77)$ \\
\hline Chennai $(\mathbf{n = 2 3 2})$ & $34(14.65)$ & $32(13.79)$ \\
\hline Mumbai $(\mathbf{n = 1 6 )}$ & $2(12.5)$ & $1(6.25)$ \\
\hline Hyderabad $(\mathbf{n = 9})$ & $0(0)$ & $0(0)$ \\
\hline Total & $75(16.63)$ & $83(18.40)$ \\
\hline
\end{tabular}

Table 4: City wise yield of screening by I breast scan.

\begin{tabular}{|llll|}
\hline Parameter & $\begin{array}{l}\text { Total } \\
\text { number } \\
\text { screened }\end{array}$ & $\begin{array}{l}\text { Total } \\
\text { number } \\
\text { with } \\
\text { lesions }\end{array}$ & $\begin{array}{l}\text { Percentage of } \\
\text { positive } \\
\text { lesions out of } \\
\text { screened }\end{array}$ \\
\hline City & & 16 & 8.24 \\
\hline Bengaluru & 194 & 10 & 4.31 \\
\hline Chennai & 232 & 5 & 31.25 \\
\hline Mumbai & 16 & 0 & 0 \\
\hline Hyderabad & 9 & 31 & 6.87 \\
\hline Total & 451 & & \\
\hline Age group in years & 88 & 5 & 5.68 \\
\hline$<24$ & 192 & 10 & 5.21 \\
\hline 25 to 29 & 10 & 11.11 \\
\hline 30 to 34 & 90 & 5 & 8.92 \\
\hline 35 to 39 & 56 & 1 & 5.26 \\
\hline 40 to 44 & 19 & 0 & 0 \\
\hline 45 to 49 & 4 & 0 & 0 \\
\hline $\begin{array}{l}\text { More than } \\
50\end{array}$ & 0 & 31 & 6.87 \\
\hline Total & 451 & & \\
\hline
\end{tabular}

In Bengaluru city, $20.10 \%$ of participants had a family history, and $25.77 \%$ had a personal history of breast cancer. In Chennai city, $14.65 \%$ ha ad family history and 
$13.79 \%$ a had personal history of breast cancer. In Mumbai, city $12.5 \%$ a had family history and $6.25 \%$ had a personal history of breast cancer. In Hyderabad city, no one had a family history and personal history of breast cancer (Table 3).

Out of the 451 women screened, $31(6.87 \%)$ had positive findings in the Scan and were referred for further evaluation (Table 4). The feedback was collected from

Table 5: Customer satisfaction rate of different aspects of the screening process on a Likert scale of 0 to 5 ( 0 being poor and 5 being great).

\begin{tabular}{|llllll|}
\hline City & Bengaluru & Chennai & Mumbai & Hyderabad & Average \\
\hline $\begin{array}{l}\text { My clinicare scan } \\
\text { (iBreast }\end{array}{ }^{\text {TM }}$ Scan) & 4.8 & 4.8 & 4.7 & 4.9 & 4.8 \\
\hline Customer service & 4.9 & 4.9 & 4.9 & 4.9 & 4.9 \\
\hline Room, ambience, cleanliness & 4.8 & 4.8 & 4.8 & 4.7 & 4.77 \\
\hline Overall experience & 4.8 & 4.8 & 4.8 & 4.9 & 4.82 \\
\hline Average & 4.8 & 4.8 & 4.8 & 4.8 & 4.8 \\
\hline
\end{tabular}

\section{DISCUSSION}

In spite of effective, low-cost techniques of early detection for breast cancer, the majority are detected in advanced stages. ${ }^{13}$ Poor awareness regarding disease, signs/symptoms, the social stigma of cancer coupled with limited access to screening, early diagnosis and health services. ${ }^{14}$ As a result, fewer than $30 \%$ of patients in India survive more than five years after diagnosis. ${ }^{14,15 .}$

In the present study, a total of 1080 female employees were present in the approached IT companies. Family history of breast cancer ranged from $0-20 \%$ in various study centres. All females included were educated and employed. Despite inviting 1080 participants, only $41.75 \%$ turned up for the screening program. The acceptance rate of screening varied from as low as $18 \%$ to $65 \%$ in different cities. Studies conducted in western settings have reported considerably higher acceptance rates ${ }^{16}$ In a study by Khandelwal. ${ }^{17}$ about 1420 Indian women were requested to participate in a breast cancer screening study, but only $1300(91.5 \%)$ population agreed to participate. The study setting of this study was not explicitly specified but was likely to be in health care institutional setting led by trained community health workers well acquainted with the community. Many reasons have been proposed for low acceptance of breast cancer screening. The reason stated by Vidyarthi, A. et al. ${ }^{16}$ were that even well-educated, affluent, younger Indian women face embarrassment and anxiety due to lack of awareness. These women mainly had emotional rather than a logistic barrier to seeking treatment for breast cancer. ${ }^{16}$ This emphasizes the need for a culturally appropriate, targeted health education programmes to increase the acceptance of cancer screening in general and more so of breast cancer. the participants, and the average score of all participants was computed. It was seen that iBreast ${ }^{\mathrm{TM}}$ Scan was highly accepted by all participants. Customer service, screening location and overall experience were deemed good by the participants with an average score of 4.8 (Table 5). 
Khandelwal mentioned in their study that women were taking iBE test were comfortable, and the procedure was socio-culturally acceptable, even in the rural environment. The reason being its radiation-free and painless nature. Breast examination by a radiation-free and painless electro-mechanical handheld breast palpation device (iBreast $\left.{ }^{\mathrm{TM}}\right) .{ }^{17}$

It is important to catch breast cancer at its earlier stage as it leads to better survival rate, reduces the cost of treatment and the overall burden of breast cancer, which is especially needed in developing countries like ours. ${ }^{19}$ The iBreast $\mathrm{t}^{\mathrm{TM}}$ has a potential to be a promising tool in providing effective diagnosis after breast examinations even in young women with dense breasts. It can prove to be a boon in low-resource settings in catching breast cancer at its early stages. ${ }^{10}$ Moreover, it has the advantage of requiring less screening infrastructure. ${ }^{19}$ However, this requires further research and investigation.

The qualitative exploration of the data showed that women's experiences of $\mathrm{iBE}$ in the breast screening setting were pleasant. Additionally, the experienced staff and well-organized screening programme, the entire process was successful. However, we did not conduct an in-depth qualitative study on patient experience with iBreast ${ }^{\mathrm{TM}}$ Scan with face to face interview or focus group discussions. In future, it's recommended to conduct a phenomenological qualitative study with a semistructured interview in order to get new insights into an area which has received little or no prior qualitative research attention.

The limitation of our study was that the low overall response rate in the community. Secondly, only women from the IT sector were invited to take part in the study. They were well educated and belonged to the urban area, as compared to most Indian women. Another limitation was the retrospective nature of the study. Additionally, the qualitative data that was collected was also limited and did not capture the emotions and in-depth experience of the women who underwent screening. Due to these limitations, the study could only be generalized with caution. The future investigation must focus on the acceptance rate of iBreast $^{\mathrm{TM}}$ screening in different settings, factors determining the acceptance and interventions effective in increasing the acceptance rates. Also, prospective studies with well-established referral mechanisms are needed to document the diagnostic accuracy of iBreast ${ }^{\mathrm{TM}}$ as compared to existing screening method.

\section{CONCLUSION}

iBreast is a safe, convenient and handy device to screen for breast cancer in educated/motivated women. The experience was pleasant and deemed safe by majority. iBreast should be considered for screening for rural population based on the present experience.

\section{ACKNOWLEDGMENTS}

Authors would like to thank the technical support in data entry, analysis and manuscript editing by "Evidencian Research Associates"

Funding: No funding sources

Conflict of interest: None declared

Ethical approval: The study was approved by the Institutional Ethics Committee

\section{REFERENCES}

1. Malvia S, Bagadi SA, Dubey US, Saxena S. Epidemiology of breast cancer in Indian women. Asia Pac J Clin Oncol 2017;13(4):289-95.

2. WHO. Breast Cancer Awareness Month 2019.: WHO; 2019. Available at: https://www.iarc.fr/featured-news/breast-cancerawareness-month-2019/. Accessed on 15 May 2020.

3. Ferlay J, Soerjomataram I, Dikshit R, Eser S, Mathers C, Rebelo M, et al. Cancer incidence and mortality worldwide: sources, methods and major patterns in GLOBOCAN 2012. Int $\mathbf{J}$ Cancer 2015;136(5):E359-86.

4. Shrivastava SR, Shrivastava PS, Ramasamy J. Self Breast Examination: A Tool for Early Diagnosis of Breast Cancer. Am J Public Health Res 2013;1(6):135-9.

5. Kumar JU, Sreekanth V, Reddy HR, Sridhar AB, Kodali N, Prabhu AS. Screening Mammography: A Pilot Study on Its Pertinence in Indian Population by Means of a Camp. J Clin Diagn Res 2017;11(8):2932.

6. Grosse Frie K, Ramadas K, Anju GA, Mathew BS, Muwonge R, Sauvaget CS, et al. Determinants of participation in a breast cancer screening trial in trivandrum district, India. Asian Pac J Cancer Prev 2013;14(12):7301-7.

7. Gangane N, Ng N, Sebastian MS. Women's Knowledge, Attitudes, and Practices about Breast Cancer in a Rural District of Central India. Asian Pac J Cancer Prev 2015;16(16):6863-70.

8. Anderson BO, Cazap E, El Saghir NS, Yip CH, Khaled HM, Otero IV, et al. Optimisation of breast cancer management in low-resource and middleresource countries: executive summary of the Breast Health Global Initiative consensus, 2010. Lancet Oncol 2011;12(4):387-98.

9. Bhattacharya S, Sharma N, Singh A. Designing culturally acceptable screening for breast cancer through artificial intelligence-two case studies. J Family Med Prim Care 2019;8(2):760-2.

10. Kr A. Non-invasive and low-cost technique for early detection of clinically relevant breast lesions using a handheld point-of-care medical device (iBreast): Prospective three-arm triple-blinded comparative study for breast cancer screening in low resource setting countries. Annals of Oncology. 2019;30(Supplement_3). 
11. Jahagirdar D, Upganla P. Study of accuracy of ibreast exam lump-experience of a tert. IJCIR 2019;5(2(A):1462-6.

12. Pilevarzadeh M. Women's Perspective of Breast Self-examination. Int J Biomed Sci 2016;12(3):1159.

13. Sankaranarayanan R, Ramadas $K$, Thara $S$, Muwonge R, Prabhakar J, Augustine P, et al. Clinical breast examination: preliminary results from a cluster randomized controlled trial in India. J Natl Cancer Inst 2011;103(19):1476-80.

14. Shridhar K, Dey S, Bhan CM, Bumb D, Govil J, Dhillon PK. Cancer detection rates in a populationbased, opportunistic screening model, New Delhi, India. Asian Pac J Cancer Prev 2015;16(5):1953-8.

15. Mallath MK, Taylor DG, Badwe RA, Rath GK, Shanta V, Pramesh CS, et al. The growing burden of cancer in India: epidemiology and social context. Lancet Oncol 2014;15(6):e205-12.

16. Vidyarthi A, Soumya A, Choudhary S, Sinha B. Barriers to breast cancer screening in young Indian women: A tale of two cities. Asian J Exp Sci 2013;27:29-35.

17. Khandelwal R. Health worker led breast examination in rural India using electro-mechanical hand-held breast palpation device. J Cancer Prev Curr Res 2018;9(3):138-41.

18. Kerlikowske K, Smith-Bindman R, Abraham LA, Lehman CD, Yankaskas BC, Ballard-Barbash R, et al. Breast cancer yield for screening mammographic examinations with recommendation for short-interval follow-up. Radiol 2005;234(3):684-92.

19. Broach RB, Geha R, Englander BS, DeLaCruz L, Thrash H, Brooks AD. A cost-effective handheld breast scanner for use in low-resource environments: a validation study. World J Surg Oncol 2016;14(1):277.

20. RamBihariLal Shrivastava S, Saurabh Shrivastava P, Ramasamy J. Self Breast Examination: A Tool for Early Diagnosis of Breast Cancer. Am J Public Health Res 2013;1(6):135-9.

21. Fotedar V, Seam RK, Gupta MK, Gupta M, Vats S, Verma S. Knowledge of risk factors and early detection methods and practices towards breast cancer among nurses in Indira Gandhi Medical College, Shimla, Himachal Pradesh, India. Asian Pac J Cancer Prev 2013;14(1):117-20.

Cite this article as: Bhutale R, Rajani V, Bhashyakarla V, Gunda S, Bhat A. Experience and yield of mass breast screening among working women in major cities of India: a mixed-method study. Int J Reprod Contracept Obstet Gynecol 2020;9:4215-20. 